\title{
A atualidade das contribuições de Karl Marx e Friedrich Engels para a crítica das reformas neoliberais na educação no Brasil
}

\section{The actuality of the contributions of Karl Marx and Friedrich Engels to the critique of neoliberal reforms in education in Brazil}

\section{La realidad de las contribuciones de Karl Marx y Friedrich Engels a la crítica de las reformas neoliberales en la educación en Brasil}

\author{
Gonçalves, Leonardo Dorneles ${ }^{1}$ (Rio Grande, RS, Brasil) \\ ORCID ID: https://orcid.org/0000-0001-8093-8493 \\ Santos,' Magda Gisela Cruz dos² (Pelotas, RS, Brasil) \\ ORCID ID: https://orcid.org/0000-0001-8971-9609 \\ Santos, Franciele Soares dos ${ }^{3}$ (Francisco Beltrão, PR, Brasil) \\ ORCID ID: https://orcid.org/0000-0003-1223-1650
}

\begin{abstract}
Resumo
O artigo aborda a atualidade dos referenciais de Karl Marx e Friedrich Engels para a análise crítica do reformismo neoliberal ortodoxo. Com base nas categorias trabalho, politecnia e omnilateralidade, destacamos a distinção fundamental da relação trabalho e educação que fundamenta sua concepção de educação/formação da classe trabalhadora, daquela proposta pelas reformas neoliberais da atualidade brasileira. $\mathrm{O}$ texto é resultado dos estudos bibliográficos exploratórios realizados em três pesquisas em nível de doutorado, que adotaram como referenciais as principais obras de Marx e Engels. O estudo demonstra que, as categorias educação politécnica e omnilateralidade nas obras dos autores expressam a possibilidade de uma relação entre trabalho e educação que contribua para a superação da sociedade de classes. Constituem, portanto, fundamentos para a análise crítica das reformas neoliberais e para a consolidação do projeto de educação que importa para a classe trabalhadora.
\end{abstract}

Palavras-chave: Trabalho. Politecnia. Omnilateralidade. Educação. Reformas neoliberais.

\begin{abstract}
The article discusses the actuality of the references of Karl Marx and Friedrich Engels for the critical analysis of orthodox neoliberal reformism. Based on the categories work, polytechnics and omnilaterality, we highlight the fundamental distinction of the relationship between work and education that underlies its conception of education/training of the working class, from that proposed by the neoliberal reforms of the Brazilian present day. The text is the result of exploratory bibliographic studies carried out in three doctoral studies, which adopted as references the main works of Marx and Engels. The study demonstrates that the categories polytechnic education and omnilaterality in the authors' works express the possibility of a relationship between work and education that contributes to the overcoming of class society. They are, therefore, the basis for the critical analysis of neoliberal reforms and for the consolidation of the education project that matters to the working class.
\end{abstract}

Keywords: Work. Polytechnics. Omnilaterality. Education. Neoliberal reforms.

\section{Resumen}

El artículo analiza la realidad de las referencias de Karl Marx y Friedrich Engels para el análisis crítico del reformismo neoliberal ortodoxo. Sobre la base del trabajo de las categorías, politécnicos y omnilateralidad, destacamos la distinción fundamental de la relación entre el trabajo y la educación que subyace a su concepción de la educación/formación de la clase trabajadora, a partir de la propuesta por las reformas neoliberales de la actualidad brasileña. El texto es el resultado de estudios bibliográficos exploratorios realizados en tres estudios de doctorado, que adoptaron como referencias

\footnotetext{
1 Professor do Instituto de Educação - Políticas Públicas da Educação da Universidade Federal do Rio Grande FURG. dorneles05@gmail.com

2 Professora da Educação Básica, coordenadora pedagógica e supervisora de estágio docente, na rede pública estadual e municipal de Pelotas. magdacs81@yahoo.com.br

3 Professora adjunta da Universidade Estadual do Oeste do Paraná. sfrancielesoares@gmail.com
} 


\section{Revista Labor}

Programa de Pós-graduação em Educação, Universidade Federal do Ceará

Fortaleza-CE-Brasil

las principales obras de Marx y Engels. El estudio demuestra que las categorías de educación politécnica y omnilateralidad en las obras de los autores expresan la posibilidad de una relación entre el trabajo y la educación que contribuya a la superación de la sociedad de clase. Son, por lo tanto, la base para el análisis crítico de las reformas neoliberales y para la consolidación del proyecto educativo

Palabras clave: Trabajar. Politécnicos. Omnilateralidad. Educación. Reformas neoliberales.

\section{Introdução}

A atualidade da crise regressivo-destrutiva do capital (MESZÁROS, 2009) tem favorecido o fato de que as perspectivas reformistas se apresentem como as únicas viáveis, aceitando a inexorabilidade do sistema capitalista como algo real. Nesse contexto, a educação da classe trabalhadora se apresenta como um dos importantes elementos das perspectivas reformistas que procuram apenas encontrar os mecanismos que minimizem os malefícios causados pelo modo de produção. Especialmente no contexto neoliberal ortodoxo, reforça-se a importância da relação educação e mercado de trabalho para a reprodução do modo de produção e acumulação.

Entendemos que a impossibilidade de reformas que superem as contradições do modo de produção capitalista sugere ao campo teórico a necessidade de compreender a radicalidade das proposições que apontam para a formação dos trabalhadores no sentido de sua emancipação. Dessa forma, consideramos importante e necessário retomar as críticas de Karl Marx e Friedrich Engels a fim de demonstrar as diferenças radicais entre a relação trabalho e educação proposta pela perspectiva de superação do sistema capitalista e aquela proposta pelas reformas neoliberais.

A conhecida crítica de Karl Marx e Friedrich Engels ao sistema do capital demonstra que é a organização de seu modo de produção, fundamentado na exploração e alienação do trabalho que impõe para os trabalhadores uma formação unilateral. Ainda que tenham constatado os limites da formação dos trabalhadores sob o sistema capitalista, Marx e Engels em seus escritos não descartam a possibilidade de uma educação que, vinculada ao trabalho, contribua para a superação da sociedade de classes. Entretanto, a perspectiva de formação marxiana, apesar de estar fundamentada na relação trabalho e educação, se distingue radicalmente das perspectivas reformistas do campo educacional que, de tempos em tempos, emergem no contexto capitalista. 
O caráter reformista, que se pode observar em projetos como 0 neoliberalismo ortodoxo, constitui-se no limiar entre absorção de demandas do modo de produção / regime de acumulação vigente. Também há a necessidade imperativa de agregar elementos pontuais para as massas trabalhadoras inserirem-se na dinâmica social o que consolida uma tentativa de consenso em torno de pautas antagônicas.

Considerando, pois, o horizonte do debate aqui proposto, organizamos 0 texto em três seções. Em um primeiro momento, a partir da crítica marxiana, caracterizamos os limites da dimensão formativa do trabalho sob a égide do modo de produção capitalista, e em especial no contexto das reformas neoliberais. Após, apresentamos as características fundamentais da reforma empresarial e neoliberal sobre a educação pública no Brasil. Por fim, analisamos a relação trabalho e educação expressa nas categorias de educação/formação politécnica e omnilateral, que compreendem a radicalidade da proposição de Marx e Engels para a formação da classe trabalhadora.

\section{Os limites da dimensão formativa do trabalho sob o modo de produção capitalista}

$\mathrm{Na}$ formação social capitalista, o processo de trabalho assume novas características, ainda que incorpore e combine elementos do modelo feudal. Marx e Engels se dedicaram a analisar os novos modos de organização do trabalho que emergiram com as mudanças operadas pela constituição histórica da forma social capitalista. Segundo Marx (2007a, p. 41):

A grande indústria criou o mercado mundial, preparado pela descoberta da América. O mercado mundial acelerou enormemente o desenvolvimento do comércio, da navegação, dos meios de comunicação. Este desenvolvimento reagiu, por sua vez sobre a expansão da indústria; e à medida que a indústria, o comércio, a navegação, as vias férreas se desenvolviam, crescia a burguesia, multiplicando os seus capitais e colocando num segundo plano todas as classes legadas da Idade Média.

Ao vencer os estágios do modelo artesanal e da manufatura, esse processo atinge seu ápice na organização industrial e na substituição massiva da força de trabalho pela introdução da maquinaria nas linhas de produção. Este é um fenômeno muito importante na consolidação das duas classes fundamentais no capitalismo: 
Com o desenvolvimento da burguesia, isto é, do capital, desenvolve-se também o proletariado, a classe dos operários modernos, os quais só vivem enquanto tem trabalho e só tem trabalho enquanto o seu trabalho alimenta o capital. Esses operários, constrangidos a vender-se a retalho, são mercadoria, artigo de comércio como qualquer outro; em consequência, estão sujeitos a todas as vicissitudes da concorrência, a todas as flutuações do mercado. O crescente emprego de máquinas e a divisão do trabalho despojaram a atividade do operário do seu caráter autônomo, tirando-lhe todo atrativo. O operário torna-se um simples apêndice e dele só se requer o manejo mais simples, mais monótono, mais fácil de aprender. Desse modo, o custo do operário se reduz, quase exclusivamente, aos meios de subsistência que lhe são necessários para viver e perpetuar a espécie (MARX, 2007a, p. 46).

Embora processos de exploração do trabalho de algumas classes por outras tenham acontecido nos modos de produção anteriores, é no capitalismo que a relação de exploração se radicaliza. Isso acontece, principalmente, porque passa a condicionar e a estar condicionada pela extração da mais-valia, mediante à nova divisão social do trabalho que se estabelece.

Enquanto nos modos de produção anteriores os seres humanos subjugavam o uso das ferramentas às suas necessidades, com a inserção das máquinas, é o trabalho que passa a ser subjugado ao ritmo da 'ferramenta máquina'. Assim, o sistema produtivo tem a oportunidade mais direta de controle do ritmo da produção, maior apropriação do tempo de trabalho e, consequentemente, maior apropriação dos conhecimentos dos trabalhadores pelo capital. A introdução da máquina contribuiu para a homogeneização do trabalho, transformando qualquer trabalho em força de trabalho e, com isso, foram radicais as implicações para a formação humana ${ }^{4}$ (MARX, 2013).

$\mathrm{Na}$ medida em que a indústria passa a orientar a produção da vida em sociedade, a venda da força de trabalho se torna o único meio de sobrevivência aos trabalhadores diante de seu despojamento dos meios de produção. Com isso, se emerge uma organização social cuja base está alicerçada em classes sociais antagônicas.

A distância do ser humano em relação ao trabalho sofre uma radical ampliação por meio do processo que Marx (2009) denomina como alienação, uma

\footnotetext{
${ }^{4}$ Igualmente importantes nesse processo são as demais transformações da modernidade como a insurgência do modelo científico, a ascensão dos Estados-nação e as mudanças que, ao fim e ao cabo, competem para a organização de duas classes sociais antagonicamente delimitadas e afetam a integralidade da vida em sociedade.
} 
Programa de Pós-graduação em Educação, Universidade Federal do Ceará

Fortaleza-CE-Brasil

vez que, no capitalismo, o produto do trabalho humano não é socializado de forma coletiva, justa e conforme as necessidades sociais, mas obedece a lógica da apropriação privada. Como o trabalhador não se apropria do resultado do processo de trabalho, o próprio trabalho e a produção passam a lhes ser estranhos. 0 trabalhador não se reconhece naquilo que realiza, pois a atividade é desenvolvida em prol de uma relação formalmente contratualizada e essencialmente exploratória.

Assim, Marx expõe que:

O trabalho não produz somente mercadorias; ele produz a si mesmo e ao trabalhador como uma mercadoria, e isto na medida em que produz, de fato, mercadorias em geral. [...] Com efeito, segundo este pressuposto está claro: quanto mais o trabalhador se desgasta trabalhando, tanto mais poderoso se torna o mundo objetivo, alheio que ele cria diante de si, tanto mais pobre se torna ele mesmo, seu mundo interior, [e] tanto menos [o trabalhador] pertence a si próprio (MARX, 2009, p. 80-81).

O esforço de Marx é para demonstrar a acentuada cisão que o modo de produção capitalista opera, recaindo sobre os trabalhadores a danosa consequência que lhe aparta do produto do seu trabalho e do próprio trabalho como meio de satisfação de suas necessidades objetivas e como atividade criativa e produtora de significado. É na forma capitalista de organização da produção da vida que o trabalho passa a ser "estranhado" (MARX, 2009) em sua totalidade e, assim, estão postas as condições para que os seres humanos não se reconheçam entre si, no próprio trabalho como atividade vital e como seres da natureza (MARX, 2009; 2013).

Nesse sentido, o controle do processo de trabalho é uma condição essencial para que o capital se mantenha como relação social dominante, de modo que a burguesia possa continuar a extrair índices mais elevados de produtividade, isto é, maior quantidade de valor produzido pelo trabalho em um menor período de tempo.

Para isso, de tempos em tempos, são também necessárias mudanças nos regimes de acumulação e nos modos de regulação, como define Mascaro (2013). É no âmbito dos modos de regulação que a educação dos trabalhadores se apresenta como um elemento fundamental para a ampliação do processo de controle da força de trabalho pelo capital. Entretanto, é a forma como se organiza a produção e circulação das mercadorias no âmbito da sociedade capitalista que caracteriza as demandas regulatórias, entre elas, a educação dos trabalhadores. 
A relação de exploração que marca o modo de produção capitalista está diretamente ligada à produção do excedente de tempo que o trabalhador emprega na produção de mercadorias e que não the é pago (MARX, 2013). No capitalismo, essencialmente, a luta de classes se efetiva sob essas condições. Se em outras formas sociais o trabalho produtivo poderia ser caracterizado pela produção necessária de bens úteis a manutenção da vida humana, no capitalismo, o trabalho produtivo se apresenta, desde a perspectiva marxiana, como aquela relação de exploração que produz mais valor. $O$ autor apresenta sua síntese com clareza:

A produção capitalista não é apenas produção de mercadoria, mas essencialmente produção de mais-valor. O trabalhador produz não para si, mas para o capital. Não basta, por isso, que ele produza em geral. Ele tem de produzir mais-valor. Só é produtivo o trabalhador que produz mais-valor para o capitalista ou serve à autovalorização do capital (MARX, 2013 p. 706).

Podemos perceber que a definição de trabalho produtivo em Marx abarca uma série de atividades, desde que estas estejam comprometidas com a produção de excedentes que não lhes pertencerá. Sob diferentes manifestações, a história do capitalismo tem sido reproduzida sem superar a relação de exploração na qual interessa aos capitalistas elevar a capacidade produtiva do trabalhador e, com isso, diminuir na mesma proporção o custo do seu trabalho. Para tal processo corrobora não apenas a expropriação dos conhecimentos do trabalho pelo capital, como também as diversas formas de adaptação e acomodação dos trabalhadores ao modo de sociabilidade decorrente dos diferentes contextos históricos em que o capitalismo se hegemoniza.

$\mathrm{Na}$ atualidade do contexto brasileiro, no qual o neoliberalismo ortodoxo retomou sua hegemonia, a relação capital e trabalho se torna ainda mais desfavorável para os trabalhadores. Além da crescente substituição do trabalho vivo pelo trabalho morto (maquinaria), a crescente financeirização do capital dispensa um número cada vez maior de trabalhadores dos processos produtivos. Disso resulta a precarização, a superexploração e as novas formas de trabalho escravo. A desregulamentação das relações trabalhistas, diante da significativa força de trabalho sobrante, desobriga o capital de arcar com parte dos custos pela reprodução da força de trabalho, seja pelo suprimento das necessidades mais fundamentais do trabalhador, como alimentação e saúde, seja pela formação para 

educação e saúde e com corte de direitos trabalhistas e previdenciários, são exemplos que expressam a atuação do capital através do Estado nesse sentido.

Isto, no entanto, não tem significado um desinteresse do capital em relação à formação dos trabalhadores, mas, ao contrário, o que se observa é o crescimento dos discursos em prol da ampliação e qualificação da educação de massas e a afirmação do vínculo entre educação e o mercado de trabalho. No entanto, é preciso questionar: qual o vínculo entre educação e trabalho interessa ao capital no contexto neoliberal ortodoxo? E, sobretudo, qual o vínculo entre educação e trabalho que interessa aos trabalhadores?

É nesse sentido que consideramos fundamental retomar os referenciais de Marx e Engels, pois, ao tratar da educação e apresentar as suas características, os autores expressam a necessidade da união entre o trabalho produtivo com 0 ensino, no entanto, em um sentido radicalmente oposto àquele defendido pelos reformistas do sistema capitalista. $\mathrm{O}$ que os autores apresentam sobre a temática educacional é que a sua articulação com o campo produtivo, tendo em vista uma formação politécnica para a formação omnilateral, poderá contribuir para construir as bases da superação da forma social capitalista em específico e, por sua vez, da exploração em geral, uma condição de possibilidade à emancipação humana, conforme procuramos expor a seguir.

\section{Reformas educacionais no contexto do neoliberalismo ortodoxo}

Nas últimas décadas, com a consolidação do projeto neoliberal ortodox ${ }^{5}$, é possível observar um processo de vulgarização do vocábulo reforma. $\mathrm{Na}$ avaliação de Shiroma; Campos; e Garcia (2005, p. 429), essa é "uma estratégia de legitimação eficaz na medida em que consegue 'colonizar' 0 discurso, o pensamento educacional e se espalhar no cotidiano como demanda imprescindível da "modernidade".

Ao analisar a formação dos trabalhadores nas últimas décadas, Frigotto (1996) afirma que muitos dos novos conceitos utilizados - tais como: globalização,

5 Para Harvey (2011, p. 16) "o neoliberalismo [...] se refere a um projeto de classe que surgiu no final dos anos 1970. Mascarado por muita retórica sobre a liberdade individual, autonomia, responsabilidade pessoal e as virtudes da privatização, livre-mercado, livre-comércio, legitimou políticas draconianas destinadas a restaurar e consolidar o poder da classe capitalista". 
Programa de Pós-graduação em Educação, Universidade Federal do Ceará

Fortaleza-CE-Brasil

integração, flexibilidade, competitividade, qualidade total, participação, pedagogia da

qualidade, formação polivalente e valorização do trabalhador, entre outros objetivaram redefinir a dimensão da formação humana no contexto de crise da organização e regulação fordista, desde meados dos anos 1960. Isto é, "[...] são uma imposição das novas formas de sociabilidade capitalista tanto para estabelecer um novo padrão de acumulação quanto para definir as formas concretas de integração dentro da nova reorganização da economia mundial" (FRIGOTTO, 1996, p. 41).

Essa lógica não constitui "[...] mera disfunção com efeitos passageiros, mas [é parte] da própria possibilidade de acumulação do capital, posto que a reestruturação produtiva se alimenta e dinamiza mais quanto mais produz o seu contrário: o trabalho precarizado" (KUENZER, 2002, p. 92). Assim, podemos afirmar que novas formas de alienar o trabalhador para sua inserção neste modelo produtivo são necessidades essenciais para a reprodução do sistema capitalista. Um exemplo de uma estratégia é o discurso das competências necessárias para a formação do novo trabalhador.

Quando utilizada no mundo do trabalho, a noção de competências define os conteúdos particulares de cada função na organização do trabalho. A partir disso, há a redefinição de conteúdos de acordo com as demandas das inovações tecnológicas (RAMOS, 2008). Ao ser transferida para a escola, ou seja, para a formação humana, origina a chamada pedagogia das competências ${ }^{6}$, que está diretamente articulada às transformações do mundo do trabalho, tendo relação também com a crise do capital e com o novo direcionamento dado ao padrão de acumulação capitalista.

A educação nacional sofre a influência da pedagogia das competências principalmente a partir da década de 1990, especialmente no governo Fernando Henrique Cardoso com a realização da reforma do aparelho estatal, e também por meio das diretrizes impostas principalmente pelos documentos produzidos pelo Banco Mundial (BM), que direcionaram as políticas educacionais dos países latinoamericanos. 6 "A pedagogia das competências é caracterizada por uma concepção eminentemente pragmática, capaz de
geriras incertezas e levar em conta mudanças técnicas de organização do trabalho às quais deve se ajustar. [...]
o desenvolvimento de uma pedagogia centrada nessa noção tem validade econômica-social e cultural, posto que
à educação é conferida a função de adequar psicologicamente os trabalhadores aos novos padrões de
produção" (RAMOS, 2008, p. 302). 
Assim, o pacote de reforma educativa proposto pelo BM abrangia: a prioridade na educação básica, com a melhoria da qualidade (e da eficiência) da educação como eixo da reforma educativa, dos aspectos financeiros e administrativos da reforma educativa; a descentralização e instituições escolares autônomas e responsáveis por seus resultados; a convocação da participação dos pais e comunidade na escola; a participação das ONGs em questões educativas; a alocação eficaz dos recursos para educação básica; e a definição de políticas e prioridades baseadas na análise econômica (TORRES, 1996).

No discurso neoliberal, o objetivo político de democratizar a escola depende da realização de uma profunda reforma administrativa do sistema escolar orientada pela necessidade de introduzir mecanismos que regulem a eficiência, produtividade e eficácia, ou seja, a qualidade dos serviços educacionais. A estratégia do neoliberalismo consiste em transferir a educação da esfera política para a esfera do mercado, questionando assim seu caráter de direito e reduzindo-a para a sua condição de propriedade.

Os efeitos no contexto escolar são materializados por meio da aceitação e incorporação de proposições empresariais, como do Movimento Todos pela Educação (TPE) ${ }^{7}$. Freitas (2012; 2014), Leher (2014), vêm apontando que esse movimento representa a inserção do capital financeiro no direcionamento das políticas educacionais brasileiras, que culmina na mercantilização da educação e na consolidação do que Neves (2005) denominou de pedagogia da hegemonia. Posto isto, faz-se necessário reconhecer que o movimento TPE tem como protagonistas

Itaú-Unibanco, Bradesco, Santander; os grandes meios de comunicação: Fundação Roberto Marinho, Victor Civita; corporações da indústria editorial; setores metalúrgicos, como a Vale e próprio grupo Gerdau; os representantes do agronegócio, como a Monsanto (LEHER, 2014, p. 170).

Foi sob a chancela do governo Lula que houve a fusão do Estado com os representantes do movimento TPE. Esta fusão esteve representada principalmente pela criação do Plano de Desenvolvimento da Educação (PDE), chamado PDE: Compromisso Todos pela Educação. Quer dizer, o movimento TPE conseguiu, por

\footnotetext{
7 "Os empresários além de apropriadores da riqueza socialmente produzida, assumem a função de educadores sociais, tornando-se parceiros privilegiados dos governos neoliberais. Os governos, por sua vez mercantilizam-se assumindo concepções e práticas empresariais para implementar políticas de educação, saúde, habitação e transporte, entre outras, visando a conformação de uma nova sociabilidade" (MARTINS; NEVES, 2012, p. 543). 
meio do consentimento do governo, organizar uma agenda educacional em consonância com interesses do capital para a formação dos trabalhadores.

Ainda, é no bojo de mecanismos como responsabilização, meritocracia (FREITAS, 2012), criados pelos representantes do TPE, que emerge a ideia de privatização. A privatização busca entregar o sistema público de ensino sob a forma da gestão por concessão ${ }^{8}$.

Os citados mecanismos apresentam efeitos perversos para educação e a escola. Entre eles, Freitas (2012) destaca: o estreitamento curricular; a competição entre profissionais; a pressão sobre o desempenho dos alunos e preparação para testes; fraudes; o aumento da segregação socioeconômica no território; o aumento da segregação socioeconômica dentro da escola; a precarização da formação de professores; a destruição moral do professor e do sistema público de ensino.

Feitas essas observações, cabe ainda considerar que, paralelamente ao movimento TPE, há uma espécie de rejuvenescimento da teoria do capital humano ${ }^{9}$. Tal fenômeno representa também a ofensiva do capital sobre a formação humana, na lógica de formar trabalhadores competentes para a dinâmica do mercado de trabalho contemporâneo.

Nas últimas décadas, o projeto do capital para educação vem promovendo uma espécie de apartheid educacional entre as classes sociais (LEHER, 2014). Isso acontece quando, por exemplo, estabelece o ensino do básico nas escolas por meio da ratificação de um currículo mínimo com ênfase em um "corpo de habilidades básicas de vida, suficiente para atender aos interesses das corporações e limitando a algumas áreas de aprendizagem restritas (usualmente leitura, matemática e ciências)" (FREITAS, 2012, p. 390).

Do exposto, podemos inferir que a escola, sob os grilhões do capitalismo, vem sendo subordinada a uma espécie de doutrinação permanente cujo foco é a naturalização das relações sociais, econômicas e políticas. Por isso, cabe considerarmos ainda que "a sociedade capitalista resguarda com vigor não apenas o

\footnotetext{
8 "[...] O advento da privatização de gestão introduziu na educação a possibilidade que uma escola continue sendo pública e tenha uma gestão privada (gestão por concessão) [...] Continua gratuita para os alunos, mas o estado transfere para iniciativa privada um pagamento pela sua gestão. Há um 'contrato de gestão' entre a iniciativa privada e o governo" (FREITAS, 2012, p. 386).

9 Foi Teodoro Schultz, nos Estados Unidos, que elaborou a noção de capital humano. De acordo com Frigotto (2009, p. 131), "a tese básica sustentada por Schultz (1973), e que se tornou senso comum, foi de que aqueles países, ou famílias e indivíduos, que investissem em educação acabariam tendo um retorno igual ou maior em investimentos produtivos. Por essa via se teria a chave para diminuir desigualdade entre as nações, grupos sociais e indivíduos".
} 
sistema de educação contínua, mas simultaneamente também de doutrinação permanente" (MESZAROS, 2008, p. 82).

Foram as críticas à sociedade capitalista e à educação burguesa, realizadas por Marx e Engels em seus escritos, que explicitaram a necessidade da constituição de uma pedagogia contra-hegemônica, por meio do trabalho como princípio educativo, da formação humana politécnica e omnilateral. Para Rossi (1981, p. 127), "[...] quando Marx denuncia o caráter burguês da educação industrial dentro da sociedade capitalista, ele reafirmou claramente que há uma pedagogia do capital, assim como há uma pedagogia revolucionária do trabalho".

Sem dúvida, foram Marx e Engels que elaboraram as bases para construção de uma pedagogia revolucionária de inspiração socialista com vistas a corroborar com a transformação social. De fato, os dois forjaram categorias pedagógicas imprescindíveis para a compreensão da formação humana de caráter integral, isto é, a formação de homens e mulheres como membros do gênero humano.

\section{Politecnia, omnilateralidade e a crítica da educação no contexto capitalista}

As manifestações de Marx e Engels sobre a educação e ensino escolar partem de um fundamento que é claro em toda obra: a crítica radical à sociedade e às relações sociais burguesas. No que tange à educação, tal crítica se manifesta em relação à forma como a burguesia controla a educação pública e empobrece a educação dos filhos dos trabalhadores, inclusive por permitir a influência religiosa na formação moral do povo. Diretamente, os autores confrontam o modelo educacional burguês já no "Manifesto Comunista", e afirmam que "os comunistas não inventaram a intromissão na educação. Apenas procuram modificar o seu caráter, arrancando a educação da influência da classe dominante" (MARX; ENGELS, 2007a, p. 55).

Ainda que a centralidade da formulação marxiana não seja a educação, ensino e a religião, os autores perceberam que a coexistência desses fenômenos na formação humana e social não poderia ser pormenorizada. Sobre o lugar que o Estado e a Igreja (religião) devem ocupar nas questões educacionais, Marx (2012, p. 45-46) afirma que

Absolutamente condenável é uma "educação popular sob incumbência do Estado". Uma coisa é estabelecer, por uma lei geral, os recursos das escolas públicas, a qualificação do pessoal docente, os currículos etc. e, como ocorre nos Estados Unidos, controlar a execução dessas prescrições 
legais por meio de inspetores estatais, outra muito diferente é conferir ao Estado o papel de educador do povo! O governo e a Igreja devem antes ser excluídos de qualquer influência sobre a escola. No Império prussianoalemão (e não se escapa da questão com o cômodo subterfúgio de que se trata de um "Estado futuro"; já vimos no que este consiste), é o Estado que, ao contrário, necessita receber do povo uma educação muito rigorosa (MARX, 2012, p. 45-46).

Marx nos permite afirmar que, no sentido de uma educação pública, no contexto de um Estado moderno, a influência da religião e do Estado são condições adversas e antagônicas aos interesses de uma educação dos trabalhadores. A religião como mistificadora e justificadora das formas sociais desiguais e da exploração e o Estado como expressão hegemônica dos interesses da classe dominante são características que necessitam ser superadas. Marx e Engels denunciam que a classe dominante não se preocupa com a educação e o ensino escolar dos operários e de seus filhos ao ponto de possibilitar-Ihes uma "verdadeira educação", porque o que Ihe interessa é uma instrução limitada ao ponto de aceitar como um dado natural as relações sociais estabelecidas.

Ao caracterizar a educação na perspectiva da burguesia e a forma como a classe dominante concebe a educação para os trabalhadores afirmam que:

\begin{abstract}
A burguesia inglesa é tão cruel, tão estúpida e limitada em seu egoísmo que, inclusive, nem se preocupa em inculcar nos operários a moral atual, aquela que configurou a burguesia em seu próprio interesse e para sua própria defesa! Até essa preocupação parece excessiva à burguesia que é, cada vez mais, débil; inclusive isto Ihe parece supérfluo [...] Não desejamos assinalar, finalmente, que a formação intelectual, no caso do operário possuí-la, não teria influência direta sobre o salário; que a instrução geralmente depende do nível das condições de vida, e que o burguês entende por educação moral a memorização dos princípios burgueses, e que no fim das contas a burguesia não tem os meios, nem vontade, de oferecer ao povo uma verdadeira educação (MARX; ENGELS, 2011, p. 113114).
\end{abstract}

A crítica é expressão da maneira como a burguesia de seu tempo conduz e influencia a educação dos trabalhadores. Mas, é interessante lembrar que os autores não afirmam que as obrigações do Estado com o financiamento da educação dos trabalhadores devam ser extintas, mas sim as suas influências na proposta formativa dos trabalhadores. A partir disso, destacamos que Marx e Engels entendem a importância de uma educação sob influência hegemônica dos trabalhadores, ainda que com financiamento do Estado, uma vez que os autores tiveram clareza das reais e desfavoráveis condições para implantar um projeto social 
e educativo em que o objetivo principal fosse contemplar um ensino que fortalecesse os trabalhadores.

Entendiam que a disputa no interior do Estado seria fundamental, mas para superá-lo e não para fortalecê-lo. A partir desse entendimento, eles expressam os fundamentos para uma educação que interessa a classe trabalhadora. Sempre datadas, as proposições ganham sentidos genéricos quando as entendemos no quadro geral das formulações em que os autores se situam. O significado revolucionário da proposta marxiana para a educação não reside na interpretação literal dos seus textos, mas no conjunto, no sistema conceitual e das práticas revolucionárias que constituíram Marx e Engels como expressão de uma teoria capaz de explicar as relações sociais, ao mesmo tempo em que evidenciam os mecanismos que podem engendrar transformações.

A importância dada à articulação do estudo com o trabalho ${ }^{10}$ ganha centralidade entre os textos que abordam a questão da educação e ensino escolar. Os autores entenderam que tal relação poderia colocar os trabalhadores em patamares mais qualificados, principalmente se essa combinação permitir que avancem contra a forma social capitalista, ao consolidar uma "educação pública e gratuita a todas as crianças; abolição dos trabalhos de todas as crianças nas fábricas, tal como é praticado hoje. Combinação da educação com a produção material", etc. (MARX; ENGELS, 2007a, p. 58).

Dessa forma, ampliam o sentido da educação escolar de modo que atenda as necessidades das massas trabalhadoras: "Educação popular universal e igual, sob incumbência do Estado. Escolarização universal obrigatória. Instrução gratuita". (MARX, 2012, p. 85).

Especificamente sobre educação escolar, os autores apresentam a formulação que busca combinar três movimentos que, juntos, possibilitariam aos trabalhadores avançar em relação à classe antagônica. Ao redigir as instruções aos delegados do comitê provisório do I Congresso da Associação Internacional dos Trabalhadores, Marx assim expressa o entendimento sobre educação:

\footnotetext{
10 Santos (2016) nos lembra que "é preciso reconhecer que combinação estudo/trabalho foi anunciada antes de Marx e Engels pelos socialistas utópicos do século XIX, entre eles destacam-se Thomas Morus (1480-1535), Charles Fourier (1772-1837) e Robert Owen (1771-1858) [...] Portanto a noção de união do ensino com o trabalho localiza-se inicialmente na tradição herdada pelo socialismo utópico e foi superada pelas análises de Marx e Engels a respeito das condições de vida e de trabalho. (p. 70).
} 
Por educação entendemos três coisas:

1) Educação intelectual.

2) Educação corporal, tal como a que se consegue com os exercícios de ginástica e militares.

3) Educação tecnológica, que recolhe os princípios gerais e de caráter científico de todo o processo de produção e, ao mesmo tempo, inicia as crianças e os adolescentes no manejo de ferramentas elementares dos diversos ramos industriais.

Esta combinação de trabalho produtivo pago com a educação intelectual, os exercícios corporais e a formação politécnica elevará a classe operária acima dos níveis das classes burguesa e aristocrática. $O$ emprego de crianças e adolescentes de nove a dezoito anos em trabalhos noturnos ou em indústrias, cujos efeitos sejam nocivos à saúde deve ser severamente proibido por lei (MARX; ENGELS, 2011, p. 85).

O fragmento é riquíssimo e, para nós, apresenta três pontos de destaque. Primeiro, há um amplo e articulado conceito de educação apresentado pelo autor, o que nos permite dizer que a educação, em Marx, somente se efetiva se atender diversas dimensões da formação humana. Essa noção se contrapõe frontalmente aos modelos educacionais baseados em treinamentos unilaterais, que buscam efetuar uma formação fragmentada, onde o conhecimento é restrito, a relação com o corpo e intelecto é distanciada e o domínio dos processos científicos é tratado sem relação com o mundo prático. Para Marx, a educação enquanto processo amplo de formação humana é uma prática que deve articular todas as dimensões.

Segundo, o autor apresenta a relação do ensino com o trabalho produtivo pago, o que possibilitaria a aproximação da atividade intelectual do trabalho prático, de modo que a classe trabalhadora construísse condições para: 1) superar a fragmentação do processo educativo escolar como componente que aliena os trabalhadores; e 2) construir alternativas ao modelo educacional burguês cujo fundamento é a naturalização das relações sociais capitalistas, por meio da cisão do conhecimento e das práticas educacionais. Para Marx, a questão central é que, na educação burguesa, a cisão do trabalho é funcional para o modelo de organização da sociedade e para que a sua manutenção passe, necessariamente, pela assimilação dos trabalhadores como natural. Para o autor, na medida em que existe a combinação dos estudos com o trabalho produtivo, poderão ser constituídas formas de pensar a relação trabalho - capital na perspectiva da sua superação, desde que estes processos educativos estejam alinhados com as necessidades dos trabalhadores, o que significa a superação da influência da religião e dos condicionamentos do Estado. 
Por último, Marx apresenta-nos a politecnia como domínio dos princípios gerais e científicos que sustentam o processo de produção em articulação com trabalhos práticos/manuais. Significa que, para o autor, a realização de tarefas no campo da produção, muitas vezes de forma mecanizada, limita os trabalhadores, seja pela incorporação dos componentes ideológicos da burguesia, uma vez que a formação obtida se dá estritamente no campo produtivo, seja pela limitação dos conhecimentos que restringem aos trabalhadores a execução da atividade manual. Dessa forma, para o autor:

A formação politécnica, que foi defendida pelos escritores proletários, deve compensar os inconvenientes que se derivam da divisão do trabalho, que impede o alcance do conhecimento profundo de seu ofício aos seus aprendizes. Neste ponto, partiu-se sempre do que a burguesia entende por formação politécnica, o que produziu interpretações errôneas (MARX; ENGELS, 2011, p. 138) ${ }^{11}$.

Neste contexto, a politecnia aparece como uma resposta à divisão social do trabalho que, na forma capitalista, guarda relação determinante com as classes sociais antagônicas. A Politecnia pretende oferecer condições para que, em conjunto com outras transformações fundamentais, os trabalhadores restabeleçam o controle do processo de trabalho para superar a propriedade privada e construir a emancipação humana. Assim, para Marx e Engels, a formação politécnica, ao possibilitar a união entre a formação teórica, científica e tecnológica com o trabalho produtivo, contribui para a formação dos trabalhadores acima das classes burguesas e aristocráticas. Ao superar a distância entre formação intelectual e formação manual nos limites do sistema capitalista, ela contribui para a formação do sujeito revolucionário, capaz de questionar a ordem vigente e organizar coletivamente as alternativas de superação da sociedade de classes.

Ocorre que, na forma social capitalista, o modo simplório como a politecnia foi absorvida pelas relações sociais de produção e pela política educacional atende por polivalência, que implica uma relação entre trabalho e educação radicalmente distinta daquela proposta por Marx e Engels. Em seu tempo, Marx e Engels reconheceram essa inversão e demonstraram como o capital encontra subterfúgios para incorporar elementos contraditórios como

11 Souza Junior (1999) vai sustentar que a Politecnia é constituída a partir da necessidade da produção capitalista, do seu caráter expansionista, o que passa a exigir do trabalhador capacidades e competências para atuar em diversas frentes de trabalho. Para nós, essa capacidade deve ser nominada por Polivalência. 
O verdadeiro significado da educação, para os economistas filantropos, é a formação de cada operário no maior número possível de atividades industriais, de tal modo que, se é despedido de um trabalho pelo emprego de uma máquina nova, ou por uma mudança na divisão do trabalho, possa encontrar uma colocação o mais facilmente possível. [...] A consequência seria a seguinte: se a mão de obra é excedente em um setor industrial, este excedente se voltaria imediatamente para os outros setores da indústria, de tal forma que a redução de salários em um setor levaria seguramente a uma redução geral dos salários (MARX; ENGELS, 2011, p. 114-115).

Se a formação polivalente permite ao trabalhador a transição dos lugares onde exerce o trabalho, ela não oportuniza uma formação politécnica, mas um adestramento funcional para a readequação da força de trabalho no campo produtivo. Em nosso entendimento, desde a formulação de Marx e Engels, Politecnia exige uma superação qualitativa em relação à polivalência, sobretudo pela união do trabalho intelectual e manual, ainda que isso ocorra nos limites da forma social do capital.

Em "O Capital", Marx sublinha essa perspectiva, sintetizando um conjunto de argumentos que irão sustentar a existência de escolas politécnicas para os filhos dos trabalhadores, como superação do ensino básico (limitado) e o controle do poder político pelo proletariado:

\begin{abstract}
Uma fase desse processo de revolucionamento, constituída espontaneamente com base na grande indústria, é formada pelas escolas politécnicas e agronômicas, e outra pelas écoles d'enseignement professionnel [escolas profissionalizantes], em que filhos de trabalhadores recebem alguma instrução sobre tecnologia e manuseio prático de diversos instrumentos de produção. Se a legislação fabril, essa primeira concessão penosamente arrancada ao capital, não vai além de conjugar o ensino fundamental com o trabalho fabril, não resta dúvida de que a inevitável conquista do poder político pela classe trabalhadora garantirá ao ensino teórico e prático da tecnologia seu devido lugar nas escolas operárias. Mas tampouco resta dúvida de que a forma capitalista de produção e as condições econômicas dos trabalhadores que lhe correspondem encontramse na mais diametral contradição com tais fermentos revolucionários e sua meta: a superação da antiga divisão do trabalho. O desenvolvimento das contradições de uma forma histórica de produção constitui, todavia, o único caminho histórico de sua dissolução e reconfiguração (MARX, 2013, p. $682)$.
\end{abstract}

Ao admitir a existência das escolas politécnicas na forma social capitalista, reconhece que a sua existência deverá tencionar o modelo ao 
acirramento de suas próprias contradições, o que poderá levar a sua superação.

Para Marx, a politecnia cumpre papel importante no processo de transição de uma forma histórica e social à outra, e, por isso, não assume a mesma forma, o conteúdo e fundamentos da educação burguesa (polivalência), mas supera-os. Ainda que ambas configurem uma formação multifacetada, politecnia e polivalência se distinguem radicalmente pelo horizonte ao qual cada uma se destina.

Sendo a politecnia uma configuração educativa capaz de engendrar contradições que poderão apresentar superações qualitativas à forma social atual, podemos dizer que, na perspectiva marxista, está impreterivelmente vinculada com uma formação integral e omnilateral. Nela os seres humanos poderão desenvolver de forma articulada as mais amplas e diversas dimensões da vida, alcançando a emancipação humana, processo que se inicia desde a sociedade capitalista.

Destaca-se o papel científico na formação do ser humano emancipado, uma vez que essa dimensão pode ser assegurada por uma formação politécnica, mesmo condicionada pelas contradições objetivas do capitalismo. $O$ aspecto científico tratado pelo autor, em nosso entendimento, revela a possibilidade de controle e regulação dos fenômenos sociais e da própria natureza, o que implica conhecer o funcionamento de cada fenômeno para dominar o processo produtivo. Nesse caso, a educação politécnica ocupa um lugar central para que tal possibilidade seja concretizada, o que implica também uma nova distribuição social do trabalho:

\begin{abstract}
Logo que o trabalho começa a ser distribuído, cada um passa a ter um campo de atividade exclusivo e determinado, que the é imposto e ao qual não pode escapar; o indivíduo é caçador, pescador, pastor ou crítico, e assim deve permanecer se não quiser perder seu meio de vida - ao passo que, na sociedade comunista, onde cada um não tem um campo de atividade exclusivo, mas pode aperfeiçoar-se em todos os ramos que the agradam, a sociedade regula a produção geral e me confere, assim, a possibilidade de hoje fazer isto, amanhã aquilo, de caçar pela manhã, pescar à tarde, à noite dedicar-me à criação de gado, criticar após o jantar, exatamente de acordo com a minha vontade, sem que eu jamais me torne caçador, pescador, pastor ou crítico (MARX; ENGELS, 2007, p. 36).
\end{abstract}

A distribuição social do trabalho, de acordo com as possibilidades e necessidades sociais e a abolição da propriedade privada dos meios de produção, por sua vez, possibilitaria, segundo Marx, um novo modo de sociabilidade, omnilateral, na direção do elevado grau de desenvolvimento das potencialidades 

transformações estruturais:

[...] assim a suprasunção positiva da propriedade privada, ou seja, a apropriação sensível da essência e da vida humanas, do ser humano objetivo, da obra humana para e pelo homem, não pode ser apreendida apenas no sentido da fruição imediata unilateral, não somente no sentido da posse, no sentido do ter. O homem se apropria da sua essência omnilateral de uma maneira omnilateral, portanto como um homem total (MARX, 2009, p. 108).

A politecnia, em Marx e Engels, tem por perspectiva a formação omnilateral. As formas de organização do trabalho que correspondem aos estágios históricos em que a formação politécnica e a omnilateralidade podem se concretizar é um dos elementos que as diferencia. Entretanto, a busca pela superação do modelo capitalista de produção, bem como o lugar que o conhecimento científico ocupa no desenvolvimento das potencialidades humanas, são elementos que as aproximam e que permitem distinguir as propostas de educação/formação voltadas para a superação do trabalho explorado e da sociedade de classes, daquelas proposições educativas voltadas às reformas e ajustes no modo de produção e acumulação capitalista, conforme se observa nas reformas neoliberais da atualidade brasileira.

Fundamentalmente é o trabalho quem determina as formas de consciência, ainda que outras manifestações humanas contribuam sobremaneira para a sua formação, como é o caso das lutas políticas pela garantia de direitos, etc. Diante disso, diferentemente das propostas reformistas neoliberais, nas quais a educação é considerada um dos principais motores dos ajustes no âmbito do trabalho tendo em vista o aumento da mais-valia, na perspectiva marxiana, a formação humana decorre fundamentalmente das relações de produção da vida. Portanto, qual o vínculo entre educação e trabalho que interessa aos trabalhadores? A educação que interessa aos trabalhadores deve, portanto, estar alicerçada na perspectiva da superação do modo de produção capitalista, o qual deve ser questionado por uma educação politécnica alicerçada sob bases críticas, que adentre as contradições da sociedade de classes também no âmbito da produção e reprodução do conhecimento, assim como fizeram Marx e Engels. 


\section{Considerações finais}

Embora haja impossibilidade de uma formação humana plena e integral sob o modo de produção capitalista, Marx e Engels não consideraram a educação dos trabalhadores como algo de menor importância para seu processo de emancipação. Ainda que em textos esparsos, os autores discorreram sobre a relevância de uma formação dos trabalhadores que contribua para a superação da sociedade de classes. Foi com esse intuito que Marx e Engels elaboraram sua proposta de formação politécnica.

Conforme procuramos demonstrar ao longo do artigo, a formação politécnica no horizonte marxiano somente pode ser compreendida se relacionada a uma perspectiva de uma sociedade que supere o capitalismo, na qual se concretize a possibilidade de uma formação omnilateral, a partir de novas relações entre sociedade e educação. Nesse sentido, destacamos que a relação entre trabalho e educação expressa na obra de Marx e Engels não se confunde com as perspectivas defendidas pelo sistema capitalista em suas diferentes configurações, como podemos evidenciar no atual contexto neoliberal.

No contexto neoliberal, as propostas de formação de um trabalhador multifuncional, proativo, criativo e flexível se vinculam às exigências da reestruturação produtiva que requer o ajuste permanente da força de trabalho e a produção da conformação à ordem social vigente. De modo geral, para a ampla parcela da população, se destinam propostas que visam uma formação reduzida às demandas do mercado de trabalho, portanto, aligeirada, pragmática, reducionista, utilitarista, mecanicista, com vista à maior circulação dos trabalhadores pelos diferentes postos de trabalhos. Ao mesmo tempo, se reproduz a dualidade que caracteriza a educação na sociedade capitalista ao destinar às classes dominantes uma formação de cunho mais teórico, científico, destinada à ocupação dos cargos de gestão do sistema. Sem dúvida, isso expressa a preocupação da classe dominante em doutrinar permanentemente os trabalhadores para que estes estejam embebidos dos valores da sociedade capitalista. Como já alertava Suchodolski (1976, p. 10)

[...] a educação é um instrumento nas mãos da classe dominante que determina seu caráter de acordo com seus interesses de classe [...] 0 sistema de ensino e o sistema educativo, que na realidade são um instrumento dos seus interesses, embelezam-se de palavras bonitas acerca da liberdade e das possibilidades de desenvolvimento. 
Como analisamos no decorrer deste texto, a relação trabalho e educação que se expressa nas reformas neoliberais sintetiza a ideia da educação como indutora dos ajustes do sistema produtivo. Conforme Freitas (2018), o desafio, então, é colocar a educação escolar na direção da construção de projetos e estratégias com potencial questionador e transformador das reformas neoliberais, ou seja, direcionadas e comprometidas com a formação integral.

As contribuições de Marx e Engels constituem referências atuais e fundamentais não apenas para a crítica das reformas neoliberais como para a elaboração da proposta educativa que interessa aos trabalhadores.

Em sentido oposto às reformas neoliberais, as principais categorias que exprimem a concepção de formação humana na obra de Marx e Engels, politecnia e omnilateralidade, partem da relação intrínseca e dialética da formação humana com o trabalho. Assim, para os autores, a educação dos trabalhadores precisa alimentar, teórica e praticamente, o processo de superação da sociedade de classes e, portanto, deve estar imprescindivelmente atrelada às mudanças estruturais da sociedade atual, sobretudo, aquelas relacionadas ao trabalho.

A educação, desde o prisma da classe trabalhadora, dialoga com as transformações que tensionem a superação da exploração do trabalho, que fomentem a sua socialização e do tempo livre, a partir da atualidade histórica do modo de produção. Por isso, os escritos de Marx e Engels sobre educação podem ser considerados atuais e ainda se constituem como referências fundamentais para a análise do nosso tempo histórico. Reforçamos que há um importante legado nestes escritos que nos provoca potencializá-los no exercício de, como destaca Freitas (2017, p. 234), "[...] extrair alguns requisitos para qualificar melhor a formulação de propostas pedagógicas contra-hegemônicas". Este deve ser o elemento presente nas proposições educativas e políticas educacionais que se referem à formação/educação dos trabalhadores, de modo que seja possível superar as perspectivas reacionárias e reformistas.

\section{Referências bibliográficas}

FREITAS, Luis Carlos de. A reforma empresarial da educação: nova direita, velhas ideias. São Paulo: Expressão Popular, 2018. 
Programa de Pós-graduação em Educação, Universidade Federal do Ceará

Fortaleza-CE-Brasil

FREITAS, Luiz Carlos de. A pedagogia socialista: devolvendo a voz aos pioneiros da educação russa. In. CALDART, Roseli, BÔAS, Rafael Litvin Villas (orgs). Pedagogia socialista: legado da revolução russa de 1917 e desafios atuais. São Paulo: Expressão Popular, 2017.

FREITAS, Luiz Carlos de. Os empresários e a política educacional: como o proclamado direito à educação de qualidade é negado na prática pelos reformadores empresariais. In: Boletim de Educação - Número 12. II Encontro Nacional de Educadoras e Educadores da Reforma Agrária - II ENERA: Textos para estudo e debate. MST. São Paulo, 2014.

FREITAS, Luiz Carlos de. Os reformadores empresariais da educação: da desmoralização do magistério à destruição do sistema público de educação. In: Educação e Sociedade. Campinas, v. 33, n.119, p.379-404. Abr. jun. 2012.

FRIGOTTO, Gaudêncio. Educação e Crise do Capitalismo Real. 2a ed. São Paulo: Cortez, 1996.

FRIGOTTO, Gaudêncio. Escola e trabalho numa perspectiva histórica: contradições e controvérsias. Sísifo / Revista Ciências da Educação. n.ำ 9, maio/agosto p.129136, 2009.

HARVEY, David. O enigma do capital: e as crises do capitalismo. São Paulo, SP: Boitempo, 2011.

KUENZER, Acácia. Exclusão includente e inclusão excludente: a nova forma de dualidade estrutural que objetiva as novas relações entre educação e trabalho. In: Lombardi, J. C., Saviani, D. \& Sanfelice, J. L. Capitalismo, Trabalho e Educação. Campinas, SP: Autores Associados, 2002, p. 77-96.

LEHER, Roberto. Atualidade da política pública educacional e desafios da educação dos trabalhadores. In: PALUDO, Conceição. I SIFEDOC: Campo e cidade em busca de caminhos comuns. Pelotas, UFPel, 2014, p. 159-178.

MARTINS, André Silva NEVES, Lucia Maria Wanderley. Pedagogia do Capital. In: CALDART, Roseli S., PEREIRA, Isabel B., ALENTEJANO, Paulo, FRIGOTTO, Gaudêncio. Dicionário de Educação do campo. Rio de Janeiro. São Paulo: EPSJV. Expressão Popular, 2012, p.540-547.

MARX, Karl. Crítica ao Programa de Gotha. São Paulo: Boitempo, 2012.

MARX, Karl. ENGELS, Friedrich. A ideologia alemã. São Paulo: Boitempo, 2007.

MARX, Karl. ENGELS, Friedrich. Manifesto Comunista. São Paulo: Boitempo, 2007a.

MARX, Karl. ENGELS, Friedrich. Textos sobre Educação e Ensino. Campinas, SP: Navegando, 2011.

MARX, Karl. Manuscritos econômicos-filosóficos. São Paulo: Boitempo, 2009. 
MARX, Karl. O Capital: crítica da economia política. São Paulo: Boitempo, 2013.

MASCARO. Alysson Leandro. Estado e Forma Política. São Paulo: Boitempo, 2013.

MESZAROS, István. A educação para além do capital. 2. ed. São Paulo: Boitempo, 2008.

MESZAROS, István. Crise Estrutural do Capital. São Paulo: Boitempo, 2009.

NEVES, Lúcia Maria Wanderley (org.). A nova pedagogia da hegemonia: estratégias do capital para educar o consenso. São Paulo: Xamã, 2005.

RAMOS, Marise Nogueira. Pedagogia das Competências. In: BRASIL, Isabel Pereira. LIMA, Julia Cesar França. Dicionário da educação profissional em saúde. 2.ed. Rio de Janeiro: EPSJV, 2008, p. 299-305.

ROSSI, Wagner Gonçalves. Pedagogia do trabalho: raízes da educação socialista. São Paulo: Moraes, 1981.

SANTOS, Franciele Soares dos. Trabalho educação e formação humana no MST: tensionando a forma histórica escolar à luz da pedagogia socialista. 2016. 223 f. Tese (Doutorado em Educação), Faculdade de Educação, Universidade Federal de Pelotas, Pelotas, 2016.

SHIROMA, Eneida, GARCIA, Rosalba Maria Cardoso e CAMPOS, Roselane de Fátima. Conversão de "almas" pela liturgia da palavra: uma análise do discurso todos pela educação. In: BALL, Stephen J. E MAINARDES, Jefferson. Políticas educacionais: questões e dilemas. São Paulo: Cortez, 2011, p. 222-248.

SHIROMA, Eneida. CAMPOS, Roselane Fátima. GARCIA, Rosalba Maria Cardoso. Decifrar textos para compreender a política: subsídios teórico-metodológicos para análise de documentos. In. Perspectiva, Florianópolis, v. 23, n. 02, p. 427-446, jul./dez. 2005.

SOUZA JUNIOR, Justino de. Politecnia e Omnilateralidade em Marx, Trabalho e Educação, Belo Horizonte, v.5, n.5, jan/dez, 1999, p. 98-114.

SUCHODOLSKI, Bogdan. Fundamentos de pedagogia socialista. Barcelona, Editorial Laia, 1976.

TORRES, Rosa María. Melhorar a qualidade da educação básica? As estratégias do Banco Mundial. TOMMASI, L. De; WARDE, J. M.; HADDAD, S. (Orgs.) O Banco Mundial e as políticas educacionais. São Paulo: Cortez Ed./Ação Educativa/PUCSP, 1996, p. 125-193. 


\section{Leonardo Dorneles Gonçalves}

Rio Grande, Rio Grande do Sul, Brasil

Pedagogo e Mestre pela Universidade Federal do Rio Grande - FURG. Doutor em Educação pela Universidade Federal de Pelotas - UFPel. Professor do Instituto de Educação - Políticas Públicas da Educação da Universidade Federal do Rio Grande - FURG. É pesquisador do Grupo de Estudos e Pesquisas em Políticas Educacionais, Gestão e Financiamento da Educação - GEPEFI da Universidade Estadual de Maringá, Núcleo de Estudos e Pesquisas em Políticas Educacionais NEPPE (UFPel) e Núcleo Educamemoria (FURG). Colabora com estudos junto ao Observatório dos Conflitos Urbanos e Socioambientais do Extremo Sul do Brasil (FURG). Atualmente desenvolve estudos sobre Estado, Políticas Educacionais, Ensino Médio e suas relações com as mudanças no mundo do trabalho.

E-mail: dorneles05@gmail.com

Link do Lattes: http://lattes.cnpq.br/4670380842665317

\section{Magda Gisela Cruz dos Santos.}

Pelotas, Rio Grande do Sul, Brasil

Doutora em Educação pelo Programa de Pós-Graduação em Educação da Universidade Federal de Pelotas na linha de Filosofia e História da Educação e Mestre em Educação pelo mesmo programa. Graduada em Ciências Sociais (bacharelado e licenciatura) pela Universidade Federal de Pelotas. Integrante do Grupo de Pesquisa Trabalho, Movimentos Sociais e Educação (TRAMSE) da Universidade Federal do Rio Grande do Sul. Possui experiência na área de Educação, principalmente em relação aos temas: políticas públicas, trabalho e educação, educação popular, formação integral, movimentos sociais, escola pública e Educação do Campo. Foi pesquisadora na primeira edição do Projeto Observatório da Educação do Campo em seu núcleo no Estado do Rio Grande do Sul (CAPES/INEP). Atuou como professora da Educação Básica, coordenadora pedagógica e supervisora de estágio docente, na rede pública estadual e municipal de Pelotas. Atualmente é pesquisadora do Projeto Observatório da Educação do Campo no Rio Grande do Sul (UFRGS).

E-mail: magdacs81@yahoo.com.br

Link do Lattes: http://lattes.cnpq.br/1185251604736339

\section{Franciele Soares dos Santos.}

Francisco Beltrão, Paraná, Brasil

Possui graduação em Pedagogia pela Universidade Estadual do Oeste do Paraná (2004). Mestre em Educação pela Universidade Federal de Santa Catarina (2009). Doutora em Educação pela Universidade Federal de Pelotas - UFPel (2016). Atualmente é professora adjunta da Universidade Estadual do Oeste do Paraná. Tem experiência na área de Educação, atuando principalmente nos seguintes temas: fundamentos da educação, trabalho e educação, pedagogias contra-hegemônicas e educação escolar, movimentos sociais populares do campo e educação, educação infantil e formação de professores. Membro do grupo de pesquisa: Sociedade, trabalho e educação-GESTE- Unioestecampus de Francisco Beltrão-PR.

E-mail: sfrancielesoares@gmail.com

Link do Lattes: http://lattes.cnpq.br/8310447915314417

Recebimento: 25/03/2021

Aprovação: 19/04/2021 


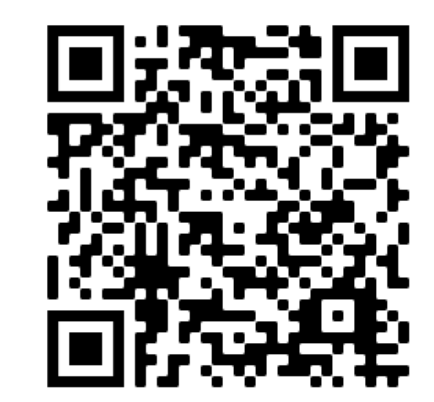

\section{Q.Code}

\section{Editores-Responsáveis}

Dr. Enéas de Araújo Arrais Neto, Universidade Federal do Ceará, UFC, Ceará, Brasil Dr. Sebastien Pesce, Universidade de Orléans, França 